\title{
Digital Literacy in Mathematics Education: Transformative Praxis in Nepal
}

\author{
Krishna Prasad Bhatt \\ Krishna.bhatt@cded.tu.edu.np \\ Lecturer \\ Central Department of Education, T.U., Kirtipur
}

\begin{abstract}
This study was carried out to sightsee amidst digital literacy together with transformative praxis of undergraduate teachers and the existing situation of the digital divide in Nepal. The entire research process of the study was guided by the post-positivism paradigm followed by survey design. This was a cross-sectional survey of school teachers were chosen as a sample by using the purposive sampling method within 183 participants. Document analysis and SPSS v.23 was used for multivariate data analysis that reaping intensive information regarding the current situation of Information Communication Technology (ICT) literacy in the context of Nepal. The results of the study reveal that there is a substantial issue of the digital divide and fear of digital dictatorship among the teachers to continue their job for the long run and compete in the twenty-first century. However, teachers are doing their job with utmost efficiency even with the lack of knowledge of digital technology.
\end{abstract}

Keywords: Digital literacy, ICT, Digital divide, Transformative Praxis, Digital dictatorship.

\section{Introduction}

Transformation is the keyword in every discipline of social phenomena. When something is transformed, its components elements undergo a profound metamorphosis so that what emerges is fundamentally different from what went before. As a body of work, critical theory has a transformative, metamorphosing impulse, so its connection to transformative learning seems natural. The kind of Transformative learning that is endemic to critical theory is learning how to create the cooperative and collective structures, systems, and processes necessary for democratic classroom praxis. When applied to the research and practice of transformative learning, critical theory, therefore, ensures that the transformation of social and policy systems is seen as necessary for any transformation of the self. If the self is understood as politically sculpted, then leaving to transform the self is a political project requiring policy transformation.

We can talk about transformation in a meaningful full sense only when capitalism has been transformed into socialism and human nature has been transformed from a focus on individual competition into a focus on collective identity and responsibility (Taylor \& Cranton, 2012). 
How can we address the problem of culturally decontextualized mathematics education through transformative praxis faced by Nepali students who, as citizens of the world's most recent democracy, are far from realizing the contribution of mathematics education to the development of a socially just, egalitarian, and pluralist society?

The school mathematics curriculum of Nepal carries a potent image of mathematics as a purely symbolic and abstract knowledge system largely disconnected from the daily life worlds of the vast majority of young people dispersed throughout this agrarian country with 129 distinct language groups and a multitude of worldviews. Although these are positive and beneficial outcomes for any transitional society, such a restrictive academic focus may be exacting a very high cost on the cultural integrity of this richly multicultural society. Research suggests that 'world standard' mathematics education in Nepal turns a blind eye to traditional mathematical practices and associated social values enacted daily by local communities, thereby serving as a powerful means of one-way enculturation into a globalizing western worldview (Luitel, 2009; Luitel \& Taylor, 2007).

This is the era of digital governance (Harari, 2018) smartphones, and the internet, from which one can access information in seconds. Students' learning needs and the challenges teachers encounter are much different than they were only a decade ago. The majority of students' needs have shifted from gaining access to information to learning how to manage the influx of information vying for their constant attention, Students now have access to all the information they will need regardless of which teachers they get or what schools they attend. According to Kaput (2000), Computational technology is a profoundly transformative force across our society.

The term "digital divide" has conventionally described disparities in access to computers and the Internet between groups of people based on one or more magnitudes of social or cultural identity. Accordingly, researchers are inclined to compare rates of physical access or actual use of, these types of machinery across groups based on race, gender, socioeconomic status, education level, disability status, native language, and other identifiers. But this conceptualization for the digital divide fails to capture the full picture of inequity and alienation recycled by these gaps and the resulting educational, social, cultural, and economic ramifications, particularly by those who are already alienated by exclusive curricula, school cultures, and most other dimensions of education. The purpose of this article is to reformulate a conceptualization of the digital divide and its relationship to education by building on a critical review of recent research and shifting the "access" paradigm toward one not based on equality of physical access but equity of access (Gorsky, 2005).

The role of educators has changed. The learning needs of students have changed. Advances in technology have led to drastic changes in societal norms, like how we communicate with one another, yet our education system has not changed, leaving both teachers and their students with unmet learning needs. Formal education used to be, and in many cases continues to be, a formerly agreed-upon exchange, wherein students exchange their time, energy, and attention to gain access to the knowledge that the teacher possesses. The knowledge was not available elsewhere or was difficult to obtain from other sources. The best students must become the teachers because they 
can demonstrate the most mastery of the content knowledge but we are observing the reverse situation in the context of Nepal. Now that access to content knowledge is instantly available to anyone with an Internet connection, the role of teachers has changed. The knowledge required to be a teacher has changed and/or become more essential to students' learning needs. Students need access to the information as well as the skills that support implementation in practical life.

We work creatively with the tension between modernism and postmodernism the dialectical relationship between these antonymic paradigms (Luitel \& Tailor, n.d). The challenges of the teachers that face today are much different from the challenges that teachers faced only a decade ago. Mezirow (1991) discussed the three types of meaning perspectives including the epistemic (what knowledge is and how we use it), sociolinguist (how language and society influence each other), and psychological. (Mezirow, 1991). A critical theory of adult learning is a theory of social and political learning. It studies the systems and forces that shape adults' lives and oppose adults' to challenge ideology, recognize hegemony, unmask power, defend the life world, and develop agency (Taylor \& Cranton, 2012).

Paulo Freire grandfather of Critical Praxis discussed liberating, emancipating, enlightening, empowering the cognitive level of the rudimentary pupil. The teacher must challenge their students' well-established ways of thinking against the banking praxis. Critical praxis is a philosophy of education and social movement that has developed and applied concepts from critical theory and related traditions to the field of education and the study of culture. Advocates of critical praxis reject the idea that knowledge is ever politically neutral and argue that teaching is an inherently political act, whether the teacher acknowledges that or not. The teacher motivates students but does not impose his/her views, explore, and question that is taken for granted knowledge and critical thinking.

Communicable pandemic diseases like COVID- 19 outbreak made the compulsion of social distance, so what should be a better mode of learning in circumstances? Every crisis comes with opportunity (Harari, 2018). The vital question is now in the academic world to continue the study whatever the situation it may be. The significant question for the twenty-first-century world is how face-to-face praxis can be converted into the virtual mode for better learning apposite for this era in an operative manner? Creativity, communication, Collaboration, and criticality are four c's that emphasize transformative praxis (Koirala, 2020) for the twenty-first world. In Nepal, several policies are made to support digital technology. For example, the National ICT policy 2015, the National Broadband Policy 2015, and the Electronic Transaction Act 2008 are some policies to guide the expansion and use of digital technology (MoCIT, 2019). These policies and other strategies too by the government are helping to pledge digitization in public services and education. In this line, the ICT Policy 2015 aimed to increase ICT accessibility to a broader public arena through ICT infrastructure development, ICT industry promotion, e-Governance, and Human Resources Development in the field of ICT (MoCIT, 2015). Equally, the Broadband Policy 2015 aimed to encompass the connectivity, public-private partnership, universal access, and diminish the digital divide and increase the access and coverage of broadband Internet service throughout the country by wireless or wired Internet connections (MoCIT, 2015). The Ministry of Communication and Information Technology has broadcasted Geo-Satellite Policy 
2020 to connect Nepal to space for reliable and high-quality information services to lessen the dependency on other commercial Geo-Satellites communication services. This initiative is also related to digital content development and distributing those contents through the satellite networks at a faster and cheaper rate (MoCIT, 2020).

Khanal et al. (2020) argued that the internet has been an indispensable capital of digital technology and information in Nepal. There were only about 7000 Internet users by 1999 (Pradhan, 1999), and this number reached nearly 30,000 in the year 2006 (Kasajoo, 2006). It grew further to $19.7 \%$ of the total population in 2016 and 34\% in 2017 (The World Bank 2020). Internet broadband penetration increased sharply from 2016 to 2017 . It penetrated $63 \%$ of the total population in the year 2019 (MoCIT, 2019).

\section{Research Objectives}

The main objectives of this study were to find the condition of the digital divide in the Mathematics classroom and to explore the practices of transformative praxis, digital literacy. The central focus of my study will around the question, in what ways has the nature of digital competency moved as transformative praxis for mathematics education in Nepal?

\section{Methodology}

This study was based on the post positivistic paradigm (Creswell, 2009) followed by Google's Cross-sectional survey questionnaire design. The data were collected from the Mathematics teachers of secondary level schools to some extent the universities in Nepal. An online survey questionnaire was designed by using Google Form. The survey link was communicated GeoGebra training webinar Society for Technology Friendly Teachers (STFT) during the COVID-19 pandemic in September 2020. The survey study is preferred in examining objective data result from empirical observations and measures. This study focused on secondary mathematics teachers. So, they were chosen as the target population, and then, by using the purposive sampling the questionnaire was sent to 350 teachers and among them, 183 teachers have responded to the survey.

\section{Result and Discussions}

There were socio-demographic variables like gender, religion, marital status, age, qualification, type of institutions, job type, the level they teach, also availability of laptops, smart phones, projectors, and time to reach school from the residence. The proportion of participants by gender was female $14.75 \%$ and male $85.25 \%$ out of the $84.2 \%$ married, almost $93.4 \%$ participants from Hindu religion, participants by age, $33 \%$ were $21-30$ years, and $77 \%$ were $31-53$ years. Among the participants, $1.6 \%$ had an intermediate, 20.2\%Bachelor's degree, and 77\% had a Master and only $1.1 \%$ higher degree (MPhil/PhD). Types of institutions have three categories as governmental $(63.9 \%)$, private $(12 \%)$, and public $(24.1 \%)$. The teaching level had three categories as basic (grades 1-8) level (21.3\%), secondary (grades 9-12) level (74.9\%), and university level (3.8\%) as per the rule of the government of Nepal. The participants having laptops were $85.8 \%$, smart phones $86.9 \%$. About $80.9 \%$ had professional training. The average time to reach school is found to be nearly half an hour that is 28 minutes. 
With the availability of personal digital tools like smartphones and laptops, it seems $86.9 \%$ of participants have a smartphone and $85.8 \%$ have a laptop while on the other hand obtainability of projectors and smart boards only seems $31.7 \%$ and $23 \%$ respectively. This indicates there is a huge lack of digital tools in the institution's comparison with personal devices. Most importantly there is a significant difference between observed and expected frequency on the two variables stable electricity and speed of internet in the institute. A three-point Likert scale (1= 'Agree', $2=$ 'Neutral', 3='Disagree') was formed to find which factor is supposed to be made mathematics difficult within four factors, the result in Table 1 portrays that lack of technology, psychological fear, Lack of professional development of teachers, and abstract nature of Mathematics in descending order play vital role to assume Mathematics as difficult discipline comparing others.

\section{Result and Discussions}

There were socio-demographic variables like gender,religion, maritalstatus, age, qualification, type of institutions, job type, the level they teach, also availability of laptop, smartphone, projectors and time to reach school from the residence. The proportion of participants by gender was female $14.75 \%$ and male $85.25 \%$ out of the $84.2 \%$ married, almost $93.4 \%$ participants from Hindu religion, participants by age, $33 \%$ were $21-30$ years, and $77 \%$ were $31-53$ years. Among the participants, $1.6 \%$ had an intermediate, $20.2 \%$ Bachelor's degree, and $77 \%$ had a Master and only $1.1 \%$ higher degree $(\mathrm{MPhil} / \mathrm{PhD})$. Types of institutions have three categories as governmental $(63.9 \%)$, private $(12 \%)$, and public $(24.1 \%)$. The teaching level had three categories as basic (grades 1-8) level (21.3\%), secondary (grades 9-12) level (74.9\%), and university level $(3.8 \%)$ as per the rule of the government of Nepal. The participants having laptops were $85.8 \%$, smartphones $86.9 \%$. About $80.9 \%$ had professional training. The average time to

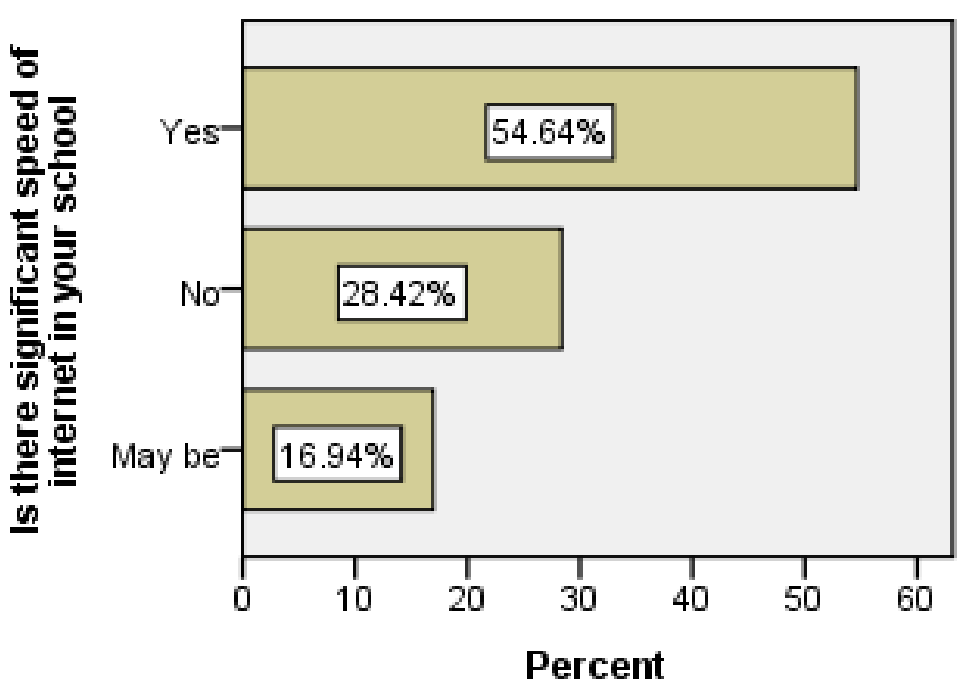
reach school is found to nearly half an hour that is 28 minutes.

With the availability of personal digital tools like smartphones and laptops, it seems $86.9 \%$ of participants have a smartphone and $85.8 \%$ have a laptop while on the other hand obtainability of projectors and smart boards only seems $31.7 \%$ and $23 \%$ respectively. This indicates there is a huge lack of digital tools in the institution's comparison with personal devices. Most importantly 
there is a significant difference between observed and expected frequency on the two variables stable electricity and speed of internet in the institute. A three-point Likert scale (1= 'Agree', $2=$ 'Neutral', 3='Disagree') was formed to find which factor is supposed to be made mathematics difficult within four factors, the result in Table 1 portray that lack of technology, psychological fear, Lack of professional development of teachers, and abstract nature of Mathematics in descending order play vital role to assume Mathematics as difficult discipline comparing others.

Table 1: Factors affecting Mathematics regarded as challenging

\begin{tabular}{|c|c|c|c|c|}
\hline Mathematics is difficult (Rating Scale) & Agree & Neutral & Disagree & Missing \\
\hline $\begin{array}{l}\text { Abstract nature of Mathematics } \\
\text { (p-value) }\end{array}$ & $56(30.6)$ & $53(29.0)$ & $62(33.9)$ & $12(6.6)$ \\
\hline $\begin{array}{l}\text { Lack of technology } \\
\text { (p-value) }\end{array}$ & $\begin{array}{l}144 \\
(78.7)\end{array}$ & $27(14.8)$ & $4(2.2)$ & $8(4.4)$ \\
\hline $\begin{array}{l}\text { Psychological fear from society } \\
\text { (p-value) }\end{array}$ & $\begin{array}{l}108 \\
(59.0)\end{array}$ & $55(30.1)$ & $9(4.9)$ & $11(6.0)$ \\
\hline $\begin{array}{l}\text { Lack of professional development of teachers } \\
\text { (p-value) }\end{array}$ & $\begin{array}{l}123 \\
(67.2)\end{array}$ & $47(25.7)$ & $7(3.8)$ & $6(3.3)$ \\
\hline
\end{tabular}

It was asked to rate challenges to improve mathematics the most 1 and the least 7 to the seven factors namely access to the internet; performance of the teacher; student background; curriculum/textbook/reference materials; access to the electricity; geographical difficulty and technological infrastructures. The result in Table 2 displays that the performance of the teacher, student background, and access to electricity is simultaneously the top challenging factors to improve mathematics achievement. In the same manner technological infrastructure, curriculum/ Textbook/Reference book, and access to the internet are second, third, and fourth topmost factors by examining modal value in Table 3 . On the other hand, examining median and mean value all factor lies in third to fourth rating scale on average.

Table 2: Challenging factors to improve Mathematics accomplishment

\begin{tabular}{llllllllll}
\hline Challenging factors to improve Math- & \multicolumn{10}{c}{ Rating (1-7) } \\
\cline { 2 - 10 } ematics achievement & 1 & 2 & 3 & 4 & 5 & 6 & 7 & Missing & Total \\
\hline Access to the Internet & 41 & 27 & 34 & 42 & 21 & 10 & 8 & 0 & 183 \\
Performance of teacher & 55 & 30 & 15 & 28 & 29 & 11 & 12 & 3 & 183 \\
Student background & 46 & 28 & 25 & 39 & 14 & 16 & 9 & 6 & 183 \\
Curriculum/Text book/Reference books & 34 & 30 & 37 & 31 & 19 & 12 & 16 & 4 & 183 \\
Access to Electricity & 41 & 28 & 31 & 32 & 15 & 21 & 15 & 0 & 183 \\
Geographical difficulty & 22 & 29 & 34 & 40 & 24 & 16 & 18 & 0 & 183 \\
Technological Infrastructure & 35 & 38 & 34 & 30 & 21 & 14 & 11 & 0 & 183 \\
\hline
\end{tabular}


Table 3: Descriptive Statistics

\begin{tabular}{lrrrrrrr} 
& $\begin{array}{c}\text { Access } \\
\text { to the } \\
\text { Internet }\end{array}$ & $\begin{array}{c}\text { Performance } \\
\text { of teacher }\end{array}$ & $\begin{array}{c}\text { Student } \\
\text { background }\end{array}$ & $\begin{array}{c}\text { Curriculum/ } \\
\text { Book/ } \\
\text { Reference }\end{array}$ & $\begin{array}{c}\text { Access to } \\
\text { Electricity }\end{array}$ & $\begin{array}{c}\text { Geographical } \\
\text { difficulty }\end{array}$ & $\begin{array}{c}\text { Technological } \\
\text { Infrastructure }\end{array}$ \\
\hline N Valid & 183 & 180 & 177 & 179 & 183 & 183 & 183 \\
Missing & 0 & 3 & 6 & 4 & 0 & 0 & 0 \\
Mean & 3.20 & 3.15 & 3.18 & 3.40 & 3.41 & 3.74 & 3.27 \\
Median & 3.00 & 3.00 & 3.00 & 3.00 & 3.00 & 4.00 & 3.00 \\
Mode & 4 & 1 & 1 & 3 & 1 & 4 & 2 \\
\hline
\end{tabular}

Around four-fifths of the teachers are using mobile and laptops interestingly it is detected that there is no statistical significance difference between the type of school and the availability of digital tools, projectors in the school, smart boards, ICT labs using chi-square test at 5\% level of significance. This indicates that most of the mathematics teachers are digitally knowledgeable and able to use the resources for their different activities and it is found that three fourth $(74.9 \%)$ of the participants have significantly increased their digital competency also one fifth $(21.9 \%)$ of them somehow about digital world, from one of the reasons for the high digital knowledge might be because the information was collected during the COVID-19 pandemic but the result seems suspicious that $57.9 \%$ of them know about Zoom, Google Meet, and Teams before the pandemic December 2019. This is obvious that the teachers learned about several digital tools and online resources during this period. This is quite noticed worthy that almost one-fifth $(20.2 \%)$ got digital support like laptop/desktop from their concerned institute while about four-fifths of them bought themselves. The non-profit or analysis supported some of the findings of the bivariate analysis and indicated a different pattern of effect for a few other variables. In the multivariate analysis, only one teaching level was found to have a statistically significant influence on the lack of digital devices. But by examining the odds ratio it seems that females are more likely to be deprived of digital devices than males, in the same manner, teachers teaching at the basic level are more likely to lack digital tools than secondary teachers which is statistically significant, also qualification having bachelor level more likely to face the lack of digital devices on the other hand teachers with more than Rs 40000 remuneration are convenient than the teachers having less than Rs 40000. Interestingly Janjati/Madheshi seems more comfortable than Khas/Arya finally Hindu looks more likely lacking digital tools. 
Table 4: Estimated odds ratios for disadvantaged from digital devices among teachers by selected predictors

\begin{tabular}{llr}
\hline & \multicolumn{1}{c}{ Predictors } & Odds ratio \\
\hline Demographic characteristics & Gender & \\
& Female (ref.) & \\
& Male & \\
& Age & \\
& $\square=40$ years (ref.) & \\
& $>40$ years & \\
Socio-economic characteristics & Teaching level & \\
& Basic (ref.) & \\
& Secondary & \\
& Qualification & \\
& Bachelor (ref.) & \\
& Master & \\
& Income & \\
& $\square=$ Rs40,000 \\
& $>$ Rs40,000 & 1.374 \\
Socio-cultural factors & Caste & \\
& Khash/Arya (ref.) & \\
& Janjati/Madhashi & 1.906 \\
& Religion & \\
& Hindu (ref.) & \\
Non-Hindu & \\
& &
\end{tabular}

An open-ended question was asked how mathematics can be made interesting the frequent answers have emerged from respondents that teachers and students should be made ICT friendly to deal with Mathematical apps like Geogebra, Mathematica, Matlab, and Mapple to visualize the abstract internal structure of mathematics together with tackle with emerging issues in the 21 st century, for that they emphasis to provide digital support by the concerned institution, also the large body of responses emphasis on the Continuous Assessment System (CAS) during the session.

Moreover, there is a consensus among the teachers for the collaboration of parents, teachers, and students, continuous professional development training, refreshment training contextual learning, and easy access of resources and detected the urgency of Technological Pedagogical Content Knowledge (TPCK) for the permanence of learning. These factors seem to play a vital role in effective transformative praxis. It's utmost necessary to transform the abstract nature of mathematics to applied nature which can be viewed as practical through sense organs and cognitive domain. 
Digital Literacy in Mathematics Education: Transformative Praxis in Nepal $/ 9$

\section{Conclusions}

Smart boards, projectors, ICT lab, nature of the institution, teaching level, and having laptops are contributing factors for transformative praxis in Mathematics Education. Digital literacy bridging the digital divide could play a significant role for virtual as well as transformative and innovative practice in Mathematics classrooms, However, this study's result was limited to 183 mathematics teachers' in the context of teachers who took part in the survey online, where there was limited use of digital tools in education before the COVID-19 while from the perspective of positive glance, pandemic boosted use of digital platform encouraged schools, and higher education institutions when closed their face-to-face classes due to the nationwide lockdown. Even though, results of this study cannot be generalized to another context due to the heterogeneous demographic look and social and cultural gap of the diverse society in the digital world. Hence, further investigation can be conducted among other subjects, students, and other social units, based on the country's diversity and large sample size. The finding of this research might provide a glimpse to the policymakers, teachers, researchers, and students to forward the step to compete in the 21 st century. Moreover, the allied stakeholders have to launch and implement some innovative programs for digital awareness for teachers, students, and parents for the utmost use of digital tools for transformative praxis in conventional classroom trends. It is also noticed that the curriculum should be updated contextual and flexible in nature.

\section{References}

Creswell, J. W. (2009). Research design: Qualitative, quantitative, and mixed methods approach. London: Sage Publications.

Creswell, J.W. (2009). Research design ( $3^{\text {rded. }}$. SAGE publications India Pvt Ltd.

Denzin, N. K., \& Lincoln, Y. S. (2018). The SAGE Handbook of Qualitative Research (Fifth Edition ed.). London: Sage Publication.

Gorski, P. (2005). Education Equity and the Digital Divide. AACE Journal, 13(1), 3-45. Norfolk, VA: Association for the Advancement of Computing in Education (AACE). Retrieved August 2, 2020 from https://www.learntechlib.org/primary/p/6570/.

Groenewald, T. (2004). A phenomenological research design illustrated. International Institute for qualitative Methodology (IIQM), 42-55.

Gutierrez, R. (2010). The Sociopolitical Turn in Mathematics Education. JRME.

Harari, Y.N. (2018). 21 Lessons for the 21st century. London: Penguin Random House UK.

Kaput, J. J. (2000). Technology as a Transformative Force in Math Education: Transforming Notations, Curriculum Structures, Content and. NCTM Standards 2000 Technology Meeting.

Kasajoo, V. (2006). Use of Internet for democracy, development and empowerment in Nepal. In

J. Hoff (Ed.), Internet, governance and democracy: Democratic transitions from Asian and European perspective (pp. 71-88). Copenhagen S, Denmark: Nordic Institute of Asian Studies. 
Khanal, B., Belbase, S., \& Joshi, D. R. (2020). Effect of Digital Awareness on Mathematics Achievements at School to University Levels in Nepal. 12(4).

Koirala, B. N. (9 May-2020)whether to win Robot or leave the teaching profession? Kathmandu: Nayapatrikadaily.com

Luitel, B. C., \& Taylor, P. C. (2007). Multi-Paradigmatic Transformative Research as/for Teacher Education: An Integral Perspective, Australia: Curtin University

Mezirow, J. (1991). Transformative Dimensions of Adult Learning. San Francisco, CA: JosseyBass.

Ministry of Communication and Information Technology (MoCIT). (2020). Geo-Satellite Policy 2020. Singhdurbar, Kathmandu: The author. https://nta.gov.np/wpcontent/ uploads/2020/07/Satellite-Policy-2077.pdf

Ministry of Communication and Information Technology (MoCIT). (2019). 2019 digital Nepal framework: Unlocking Nepal's growth potential. Singhdurbar, Kathmandu: The author. https://mocit.gov.np/pages/digital-nepal-framework

Ministry of Communication and Information Technology (MoCIT). (2015). Information and Communication Technology Policy 2015. Singhdurbar, Kathmandu: The author. https:// nta.gov.np/wp-content/uploads/2012/05/ICT-Policy-2072.pdf

Ministry of Education, Science and Technology. (2019). National curriculum framework for school education in Nepal. Singhdurbar, Kathmandu: The Author. http://lib.moecdc. gov.np/elibrary/pages/view.php?ref=2451\&k=

Pradhan, K. (1999). The Internet in Nepal: A survey report. International Information and Library Review, 31(1), 41-47. https://doi.org/10.1080/10572317.1999.10762487

Stinson, D. W., \& Bullock, E. C. (2012, May). Critical postmodern theory in mathematics education research: A praxis of. Research gate.

Taylor, E. W., \& Cranton, P. (2012). The Handbook of Transformative Learning. San Francisco, USA: JOSSEY-BASS A Wiley Imprint. 